\title{
PERAMALAN PASOKAN BAHAN BAKU DAN PENJUALAN SIR 20 DI PT. PERKEBUNAN NUSANTARA VII UNIT PADANG PELAWI KEC. SUKARAJA KAB. SELUMA
}

\section{The Forecasting of Raw Materials Supply and Sales in PT. Perkebunan Nusantara VII Unit Padang Pelawi Sukaraja}

\author{
Eka Monika Manihuruk, M. Mustopa Romdhon, dan Nusril \\ Jurusan Sosial Ekonomi Pertanian Fakultas Pertanian Universitas Bengkulu
}

\begin{abstract}
This research aims to forecast supply of raw material and sales and then to analyze the price of SIR 20 for 1 next year with a best method. Accuracy method of divination used MAD, MSE, MAPE. Analyze quantitative used time series, eksponential smoothing and Arima the development of raw materials, price of raw materials inside and outide of companies, the price of SIR 20 and selling of SIR 20 through increasing.
\end{abstract}

Keywords: forecasting, supply, raw material, sales, SIR 20

\section{PENDAHULUAN}

Salah satu sektor pertanian yang berpotensi untuk dijadikan unggulan adalah subsektor perkebunan. Sebagai salah satu subsektor yang penting dalam sektor pertanian, subsektor perkebunan mempunyai kontribusi yang signifikan terhadap perekonomian Indonesia. Sebagai negara berkembang dimana penyediaan lapangan pekerjaan merupakan masalah yang mendesak, subsektor perkebunan mempunyai peranan yang cukup signifikan. Serapan tenaga kerja oleh sektor pertanian di Indonesia adalah sebesar 27\% (2008), PDRB/PDB sebesar 20\%, dan ekspor (devisa) 40\% (BPS, 2013). PTPN VII merupakan salah satu Perusahaan yang didirikan di Kota Bengkulu bergerak di bidang industri pengelolahan bahan olah karet rakyat menjadi Crumb Rubber jenis SIR 20. Bahan Baku berasal dari bahan olah karet kebun PTPN VII Padang Pelawi dan Ketahun serta bahan olah karet Masyarakat Petani sekitar Perusahaan. Prioritas kinerja PTPN VII memproduksi Crumb Rubber jenis SIR 20 karena bahan bakunya lebih dominan dapat diolah menjadi Standard Indonesia Rubber (SIR) 20. Hambatan yang sering terjadi di Perusahaan yaitu terjadinya fluktuasi pasokan dari kebun sendiri dan fluktuasi pasokan maupun harga dari luar perusahaan. Hambatan lainnya juga fluktuasi harga SIR 20 dan permintaan SIR 20, disebabkan oleh rendahnya produksi akibat gangguan pertumbuhan dari tanaman. Hal ini dapat dibuktikan selama tahun 2014 bahwa PT. Perkebunan Nusantara Unit Padang Pelawi bagian Pawi 
Plasma tidak menghasilkan karet remah, sehingga alternatif pemenuhan bokar dari pihak ketiga. Berikut ini adalah data mengenai Produksi remah, bokar dan Produksi SIR 20. Untuk lebih jelasnya dapat dilihat pada Tabel 1.

Tabel 1. Pasokan dan Harga Karet Remah, Bokar dan Produksi SIR 20 di PT. PERKEBUNAN NUSANTARA VII UNIT PADANG PELAWI Tahun 2014

\begin{tabular}{|c|c|c|c|c|c|c|}
\hline $\begin{array}{l}\text { Bln } \\
\text { No }\end{array}$ & $\begin{array}{c}\text { Pawi } \\
\text { (ton/bln) }\end{array}$ & $\begin{array}{c}\text { Inti } \\
\text { seinduk } \\
\text { (ton/bln) } \\
\end{array}$ & $\begin{array}{c}\text { Masyarakat } \\
\text { Prov. Bkl } \\
\text { (ton/bln) }\end{array}$ & $\begin{array}{c}\text { Total } \\
\text { pasokan } \\
\text { (ton/bln) } \\
\end{array}$ & $\begin{array}{l}\text { Hasil olah } \\
\text { SIR } 20 \\
\text { (ton/bln) } \\
\end{array}$ & $\begin{array}{c}\text { Harga } \\
\text { Bokar } \\
(\mathrm{Rp} / \mathrm{Kg}) \\
\end{array}$ \\
\hline 1 & 77,853 & 53,447 & $1.330,308$ & $1.461,608$ & $1.392,370$ & 18.461 \\
\hline 2 & 64,533 & 65,304 & $1.056,095$ & $1.185,932$ & $1.232,315$ & 18.642 \\
\hline 3 & 74,940 & 57,668 & 878,577 & $1.011,185$ & $1.320,970$ & 17.441 \\
\hline 4 & 85,582 & 35,106 & $1.046,406$ & $1.167,094$ & $1.231,230$ & 17.311 \\
\hline 5 &, 946 & 71,801 & $1.344,641$ & $1.514,388$ & $1.148,875$ & 15.855 \\
\hline 6 & 102,266 & 88,029 & 948,706 & $1.139,001$ & $1.148,875$ & 16.067 \\
\hline 7 & 66,211 & 59,257 & 525,260 & 650,728 & $1.008,910$ & 13.637 \\
\hline 8 & 75,517 & 73,385 & 554,186 & 703,088 & 945,210 & 16.192 \\
\hline 9 & 71,366 & 89,335 & 760,251 & 920,952 & 875,525 & 16.038 \\
\hline 10 & 76,325 & 100,430 & 485,549 & 662,304 & 868,210 & 13.167 \\
\hline 11 & 72,967 & 95,163 & 323,883 & 492,013 & 393,085 & 13.143 \\
\hline 12 & 84,079 & 122,415 & $1.299,945$ & $1.506,439$ & 885,150 & 15.690 \\
\hline Jumlah & 949,585 & 911,340 & $10.553,807$ & $12.414,732$ & $12.490,065$ & \\
\hline Rata-rata & 79,132 & 75,945 & 879,483 & $1.034,561$ & $1.040,838$ & 15970,33 \\
\hline
\end{tabular}

Sumber: PT. Perkebunan Unit Padang Pelawi tahun 2014

Berdasarkan Tabel di atas Hasil Olah SIR 20 Pada tahun 2014 lebih besar jika dibandingkan dengan bahan bakunya disebabkan oleh Cadangan bahan baku yang disimpan di dalam gudang pada tahun sebelumnya digabungkan dengan jumlah bahan baku pada tahun 2014. PTPN VII mengambil kebijakan dalam pemenuhan bahan baku. Alternatif yang dilakukan perusahaan untuk memenuhi permintaan industri karet pasar lokal maupun mancanegara yaitu dengan pemenuhan bahan baku dari luar perusahaan. Disisi lain permintaan Bahan karet alam, saat ini mengalami peningkatan namun produksi perusahaan lebih kecil dibandingkan produksi kebun rakyat. Alternatif yang dilakukan perusahaan dengan menyimpan sisa produksi SIR 20 ke dalam gudang sebagai cadangan untuk pengiriman berikutnya. Pemenuhan pasar lokal dan mancanegara tergantung dengan permintaan pasar. Berkurangnya permintaan ini terjadi karena belum terjadinya persyaratan yang diinginkan konsumen.

Berdasarkan latar belakang di atas, maka tujuan dalam penelitian ini dapat dirumuskan sebagai berikut:

1. Mengidentifikasi Pola Perkembangan jumlah pasokan dan harga bahan baku, harga dan jumlah penjualan SIR 20 dari Januari 2009 - Maret 2015.

2. Menganalisis Peramalan jumlah Pasokan dan harga Bahan Baku, harga dan jumlah Penjualan SIR 20 Untuk 1 (dua) tahun mendatang dari Maret 2015 -

152 | Eka Monika M., M. Mustopa, R., dan Nusril, Peramalan Pasokan Bahan... 
Maret 2016 pada PTPN VII Unit Padang Pelawi dengan metode peramalan terbaik.

\section{METODE PENELITIAN}

\section{Waktu dan Tempat Penelitian}

Penelitian ini dilaksanakan pada bulan April-Mei 2015. PT. Perkebunan Nusantara VII Unit Padang Pelawi Seluma dipilih secara purposive (sengaja), dengan pertimbangan karena Perusahaan ini yang mengolah bahan baku berupa bahan olahan karet kebun dan bahan olahan karet rakyat menjadi barang setengah jadi Crumb Rubber jenis SIR 20 yang dipasarkan ke pasar lokal dan mancanegara.

\section{Metode Pengumpulan Data}

Data yang dikumpulkan dalam penelitian ini berupa data primer dan data sekunder. Data primer diperoleh dari wawancara berupa proses pembuatan dan teknis penjualan SIR 20 dan data sekunder diperoleh dari perusahaan itu sendiri yaitu data jumlah pasokan dan harga bahan baku, harga dan penjualan SIR 20, serta data produksi terakhir dari Januari 2009 Maret 2015. Data sekunder juga diperoleh dari literatur-literatur, instansi, dan lembaga yang berhubungan dengan penelitian.

\section{Analisis Data}

\section{Indeks Musim (IM/Metode Rata-rata Bergerak)}

Data yang digunakan sebagai dasar peramalan dari bulan Januari 2009 Februari 2015. Data tersebut terdiri dari data produksi, harga dan penjualan, jumlah dan harga bahan baku. Dalam mengukur derajat naik turunnya data biasanya dinyatakan dengan indeks musim atau IM. Untuk menghitung variasi dan indeks musim dengan metode rata-rata bergerak sederhana dari data asli. Prosedur penghitugan indeks variasi musim untuk runtut waktu dengan metode ini sebagai berikut:

1. Menghitung rata-rata bergerak dengan menjumlahkan data aktual (data jumlah pasokan dan harga bahan baku, harga dan penjualan SIR 20) setiap tiga bulan.

2. Menghitung rasio dari nilai yang sebenarnya dari rata-rata bergerak dengan membagi 3.

3. Data aktual (data jumlah pasokan dan harga bahan baku, harga dan penjualan SIR 20) dibagi dengan rasio dari nilai yang sebenarnya dikalikan dengan 100.

4. Untuk menghitung rata-rata redial maka rasio nilai sebenarnya terhadap rata-rata bergerak disusun menurut bulan untuk setiap tahun setelah dikeluarkan nilai terbesar dan yang terkecil.

$$
\mathrm{IM}=\frac{1200}{\text { total rata-rata redial }} \times \text { rata-rata redial }
$$


ISSN: 1412-8837

\section{Analisis Kuantitatif Pola Perkembangan dan Peramalan}

Penelitian ini menggunakan metode peramalan time series yaitu:

Metode Trend Linear

Rumus metode Trend Linear adalah sebagai berikut (Jarwanto, 2000):

$$
\mathrm{Y}=\mathrm{a}+\mathrm{bx}
$$

Keterangan:

$\mathrm{Y}=$ (Total pasokan dan harga bahan baku, harga dan penjualan SIR)

$\mathrm{a}=$ Konstanta

$\mathrm{b}=$ Koefisien

$\mathrm{x}=75$ bulan $(6,3$ tahun $)$

Metode Smoothing Eksponential

Persamaan secara matematik ditulis sebagai berikut (Jarwanto, 2000):

$$
\mathrm{Ft}=\mathrm{F}_{\mathrm{t}-1}+\mathrm{a}\left(\mathrm{A}_{\mathrm{t}-1}-\mathrm{F}_{\mathrm{t}-1}\right)
$$

Dimana:

$\mathrm{Ft}=$ Peramalan baru (total pasokan dan harga bahan baku, harga dan penjualan SIR)

$\mathrm{F}_{\mathrm{t}-1}=$ Peramalan sebelumnya

$\alpha=$ Konstanta smoothing

$\mathrm{A}_{\mathrm{t}-1}=$ Aktual periode lalu

Metode ARIMA

\section{Model Umum dan Uji Stasioneritas}

Stasioneritas berarti tidak terdapat pertumbuhan atau penurunan pada data (total pasokan dan harga bahan baku, harga dan penjualan Standard Indonesia Rubber). Data secara kasarnya harus horizontal sepanjang sumbu waktu. Dengan kata lain, fluktuasi data berada di sekitar suatu nilai rata-rata yang konstan, tidak tergantung pada waktu dan varians dari fluktuasi tersebut atau tetap konstan setiap waktu. Untuk mengetahui stasioner tidaknya data dapat diamati dari time series plot data tersebut, autocorrelation function data atau model trend linier data terhadap waktu.

Akurasi peramalan ditentukan oleh metode peramalan yang paling baik digunakan kriteria:

Mean Squared Error (MSE)

Menurut Gasperz (2004), dalam sistem peramalan, penggunaan berbagai model peramalan akan memberikan nilai peramalan yang berbeda dan nilai kesalahan yang berbeda pula dimana rumusnya adalah:

$$
M S E=\frac{\sum e^{2}}{n}
$$

Dimana nilai $e$ adalah selisih antara nilai $Y$ dengan peramalan $(Y \mathrm{t})$. Model yang memiliki MSE paling kecil adalah model persamaan yang paling baik. 
Mean Absolute Deviation (MAD)

Nilai ini dihitung dengan mengambil jumlah nilai absolut dari tiap kesalahan peramalan dibagi dengan jumlah periode data (n). Secara sistematis MAD dirumuskan sebagai berikut (Jarwanto, 2000):

$$
\mathrm{MAD}=\sum\left|\frac{\mathrm{A}_{\mathrm{t}}-\mathrm{F}_{\mathrm{t}}}{\mathrm{n}}\right|
$$

\section{Mean Absolute Percentage Error (MAPE)}

MAPE dihitung sebagai rataan diferensiasi absolut antara nilai yang diramal dan aktual, dinyatakan sebagai persentase nilai aktual. Jika memiliki nilai yang diramal dan aktual untuk $n$ periode, MAPE dihitung sebagai berikut:

$$
\text { MAPE }=\left(\frac{100}{n}\right) \sum\left|A_{t}-\frac{F_{t}}{A_{t}}\right|
$$

Dimana:

$$
\begin{aligned}
& A_{t}=\text { Aktual pada periode }-t \\
& F_{t}=\text { Peramalan pada periode }-t \\
& n=\text { Jumlah periode peramalan yang terlibat }
\end{aligned}
$$

\section{HASIL DAN PEMBAHASAN}

Tabel 1 menjelaskan secara menyeluruh bahwa, ketika persentase (\%) jumlah pasokan bahan baku tinggi maka persentase harga bahan baku dari luar perusahaan akan menurun, sedangkan persentase harga SIR akan meningkat dan berbanding lurus dengan penjualan. Begitu juga sebaliknya Ketika jumlah pasokan bahan baku turun maka harga beli bahan baku karet dari luar perusahaan akan tinggi karena ketersediaaan bahan baku terbatas dan akan menghambat proses produksi. Faktor yang menyebabkan penjualan meningkat dipengaruhi oleh jumlah permintaan pasar terhadap SIR 20 dan harga yang ditentukan oleh pasar dunia terhadap SIR 20.

Berdasarkan 3 grafik tersebut, dapat diketahui bahwa PT.Perkebunan mengalami fluktuasi pasokan bahan baku selama 6 tahun. Rata-rata pola perkembangan pasokan bahan baku dengan eksponential smoothing sebesar $1.023 .048 \mathrm{~kg} /$ bulan, trend $1.023 .946,44 \mathrm{~kg} /$ bulan, dan arima 1.026 .205 $\mathrm{kg} /$ bulan. Selama periode tahun 2009-2015 pasokan bahan baku hanya mengalami penurunan signifikan di bulan november 2014 dengan jumlah pasokan $491.090 \mathrm{~kg} /$ bulan dan tertinggi pada bulan januari 2011 dengan jumlah $1.715 .770 \mathrm{~kg} /$ bulan. 
Tabel 1. Indeks Musim Pasokan Bahan Baku, Harga Bahan Baku dan Harga SIR 20 dan Penjualan SIR 20.

\begin{tabular}{|c|c|c|c|c|c|}
\hline \multicolumn{6}{|c|}{ Indeks Musim (\%) } \\
\hline \multirow{2}{*}{$\begin{array}{l}\text { Bulan } \\
\text { No }\end{array}$} & \multicolumn{3}{|c|}{ Bahan baku } & \multicolumn{2}{|c|}{ SIR 20} \\
\hline & $\begin{array}{l}\text { Jumlah } \\
\text { Pasokan }\end{array}$ & $\begin{array}{l}\text { Harga BB } \\
\text { Dalam }\end{array}$ & $\begin{array}{c}\text { Harga Bokar } \\
\text { Luar }\end{array}$ & Harga & Penjualan \\
\hline 1 & 104,02 & 103,74 & 79,87 & 100,96 & 105,45 \\
\hline 2 & 97,94 & 90,08 & 95,70 & 100 & 99,78 \\
\hline 3 & 103,12 & 104,26 & 104,49 & 101,29 & 105,1 \\
\hline 4 & 91,37 & 98,39 & 101,92 & 99,80 & 103,09 \\
\hline 5 & 109,70 & 102,61 & 100,95 & 99,85 & 100,08 \\
\hline 6 & 103,74 & 101,83 & 104,39 & 100,10 & 100,28 \\
\hline 7 & 104,87 & 97,34 & 99,92 & 99,61 & 100,03 \\
\hline 8 & 91,29 & 102,56 & 104,04 & 100,08 & 93,23 \\
\hline 9 & 89,10 & 103,49 & 104,10 & 99,89 & 90,20 \\
\hline 10 & 100,30 & 94,60 & 98,50 & 99,84 & 100,20 \\
\hline 11 & 97,54 & 97,94 & 104,77 & 99,44 & 98,35 \\
\hline 12 & 106,99 & 103,15 & 100,36 & 99,22 & 104,21 \\
\hline Rata-rata & 100 & 100 & 100 & 100 & 100 \\
\hline
\end{tabular}

Sumber: Data Sekunder diolah dari data PT. Perkebunan VII Unit Padang Pelawi 2015

\section{Pola Perkembangan Total Pasokan Bahan Baku}

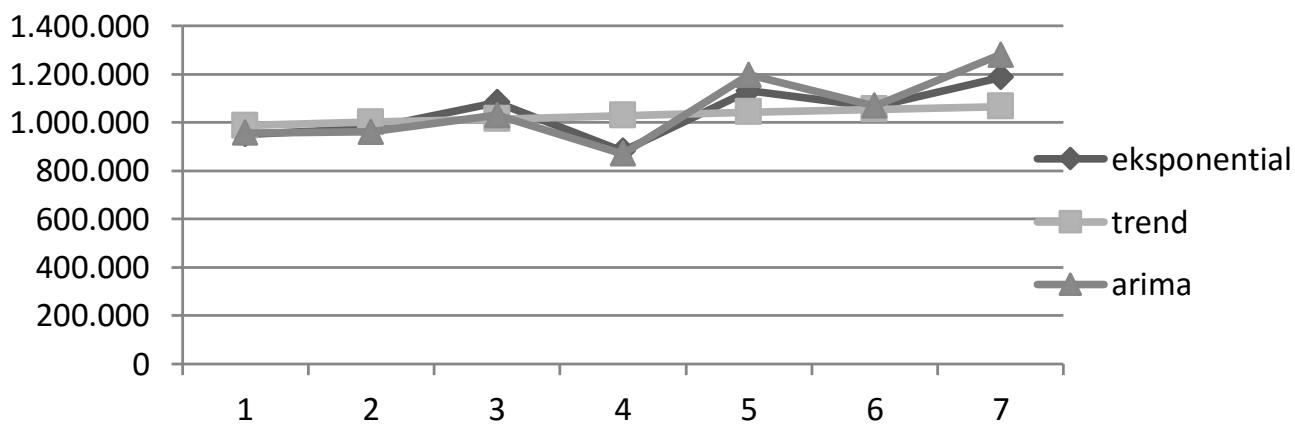

\section{Grafik 1. Grafik Pola Perkembangan Pasokan Bahan Baku}

Sumber: Data Sekunder diolah dari PT. Perkebunan VII Unit Padang Pelawi 20092015

Fluktuasi pasokan bisa terjadi disebabkan tidak tetapnya jumlah bahan baku dari kebun inti perusahaan, sehingga untuk memenuhi kebutuhan bahan baku dalam produksi alternatif yang dilakukan demgan mengambil dari ketahun dan masyarakat. Agar tidak kesulitan dalam pengadaan bahan baku sebaiknya Perusahaan menciptakan strategi yang permanen dan mempunyai hubungan timbal balik yang positif dalam bentuk aktifitas sosial CSR dan program kemitraan diharapkan mampu memberi dampak yang positif bagi

156 | Eka Monika M., M. Mustopa, R., dan Nusril, Peramalan Pasokan Bahan... 
lingkungan sekitar perusahaan. Didirikannya perusahaan tersebut diharapkan mampu mendorong pertumbuhan baik dari segi sosial dan ekonomi masyarakat sekitar.

\section{Pola Perkembangan harga bahan baku (dalam perusahaan)}

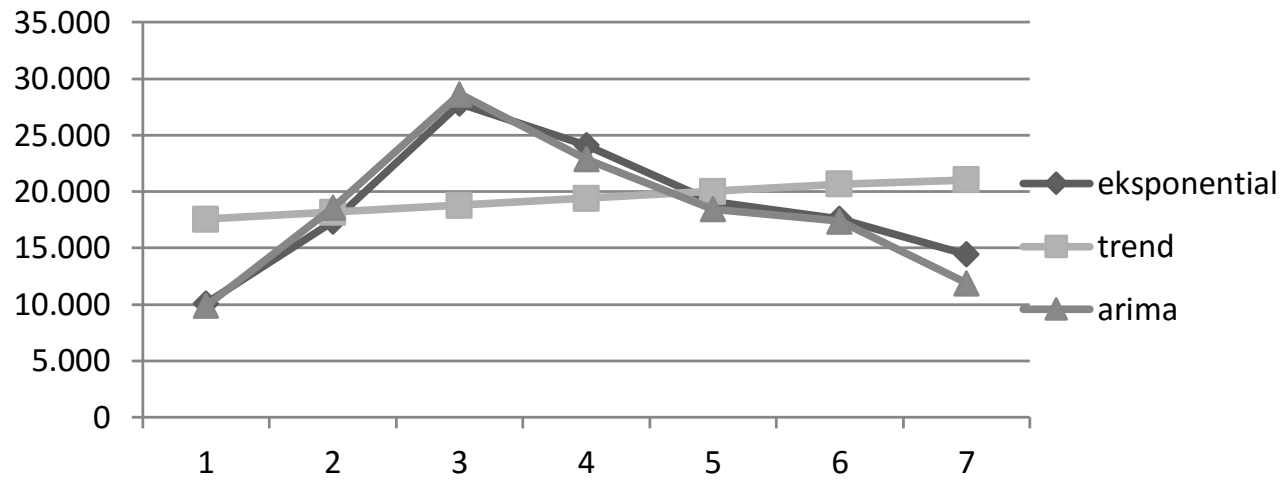

Grafik 2. Pola Perkembangan Harga Bahan Baku (Dalam Perusahaan) Sumber: Data Sekunder diolah dari PT. Perkebunan VII Unit Padang Pelawi 20092015

Berdasarkan grafik dapat dilihat bahwa, PT. Perkebunan VII Unit Padang Pelawi mengalami fluktuasi harga yang sangat signifikan dipengaruhi permintaan pasar akan produk yang berbahan baku karet sangat tinggi. Selama periode tahun 2009-2015 perkembangan harga karet cenderung tidak stabil, dapat dilihat pada grafik. Harga rata-rata bahan baku dalam perusahaan untuk analisis eksponential smoothing 19.279,62 Rp/ $\mathrm{kg}$, trend 19.190,49 Rp/kg, dan Arima 19.206,62 Rp/kg. harga dalam perusahaan memiliki harga yang tinggi karena yang menentukan harga tersebut pihak pabrik pada perusahaan itu sendiri dan juga karena hasil karet remah dari dalam perusahaan memiliki kualitas sesuai dengan standard yang ditentukan dan tidak perlu melakukan sortiran seperti pengambilan pasokan dari lainnya.

\section{Pola Perkembangan harga bokar (luar perusahaan)}

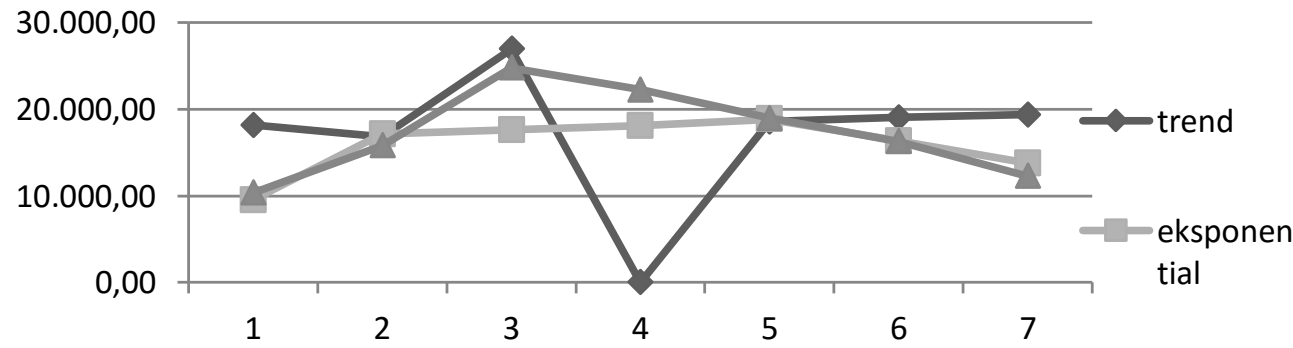

Grafik 3. Pola Perkembangan Harga Bokar

Sumber: Data Sekunder diolah dari PT.Perkebunan VII Unit Padang Pelawi 20092015 
Berdasarkan Grafik 3 dapat diketahui bahwa, PT. Perkebunan VII Unit Padang Pelawi Seluma mengalami fluktuasi harga yang diberikan pada luar perusahaan. Rata-rata harga dari luar perusahaan, berdasarkan trend analisis sebesar 17.923,56, eksponential smoothing 18.004,88 dan arima 18.344,43. Terjadinya fluktuasi harga dari luar perusahaan disebabkan oleh price maker oleh pasar dunia, dan juga perusahaan mengalami penambahan biaya seperti biaya pengangkutan bahan baku, biaya penyimpanan terhadap bahan baku yang disimpan digudang dan juga penyortiran yang dilakukan agar mutu yang dihasilkan sesuai dengan target yang telah ditentukan dan dapat bersaing dengan produk yang dihasilkan oleh perusahaan lainnya.

\section{Pola Perkembangan harga Standard Indonesia Rubber (SIR) 20}

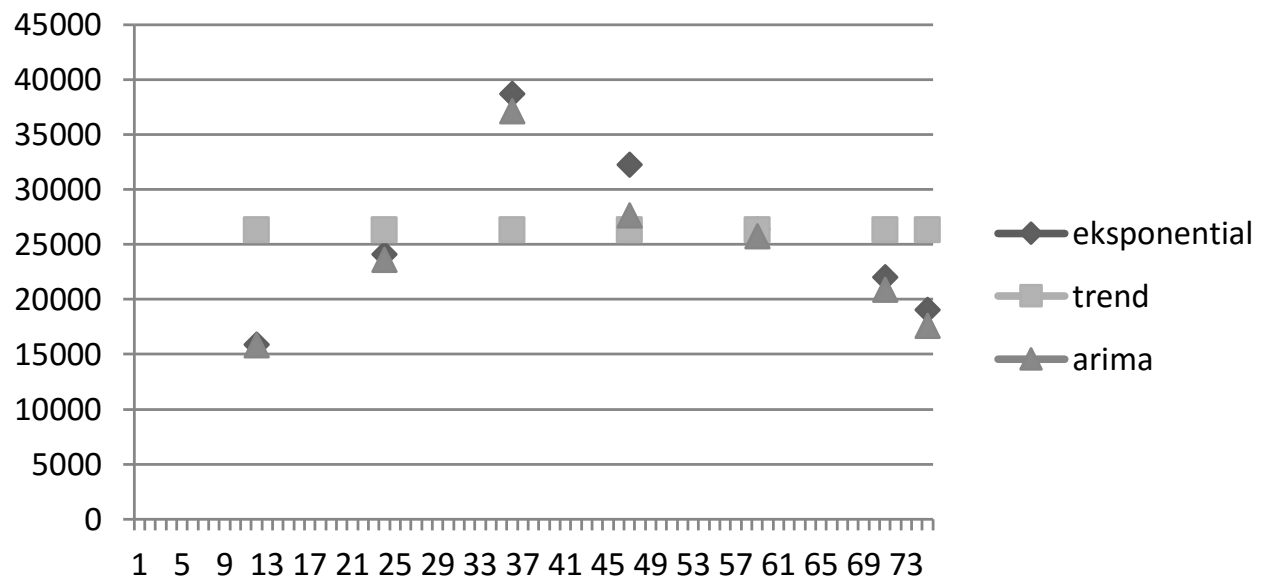

\section{Grafik 4. Pola Perkembangan Harga SIR 20}

Sumber: Data Sekunder diolah dari PT. Perkebunan VII Unit Padang Pelawi 2009-2015

Produk yang dihasilkan ini memiliki nilai yang sangat tinggi harganya setelah diolah menjadi barang setengah jadi. Nilai tambah yang didapat sekitar 70-75\%. Berdasarkan hasil penelitian, harga SIR tersebut ditentukan sesuai dengan harga pasar dunia yang ditentukan oleh negara singapura. Rata-rata harga SIR 20/Kg berdasarkan analisis eksponential smoothing 26.431,03 $\mathrm{Rp} / \mathrm{kg}$, trend 26.319,17 Rp/kg, dan Arima 24.992,53 Rp/kg. Harga SIR 20 tidak memiliki harga yang sangat signifikan, karna SIR 20 merupakan mutu produk yang paling rendah dibandingkan dengan SIR 3 dan lain-lain. Harga akan mencapai tingkat kesetabilan apabila prosess produksi dan pengiriman bisa berjalan dengan baik.

Berdasarkan Grafik 5 dapat diketahui bahwa, PT.Perkebunan VII Unit Padang Pelawi mengalami perkembangan penjualan komoditi SIR 20 yang cenderung meningkat selama 6 tahun. Selama periode tahun 2009-2015 mengalami fluktuatif. Rata-rata penjualan/bulan berdasarkan analisis eksponential smoothing Rp 4.395.702003/bulan, trend Rp 4.328.056347/bulan dan Arima Rp 3.117.865449/bulan.

158 | Eka Monika M., M. Mustopa, R., dan Nusril, Peramalan Pasokan Bahan... 
Pola Perkembangan Penjualan Standard Indonesia Rubber (SIR) 20
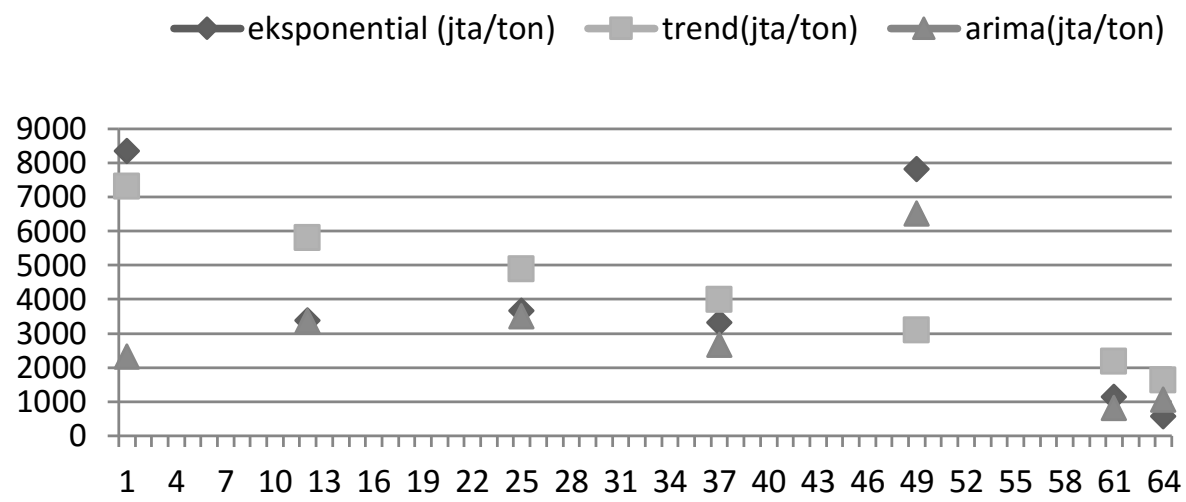

Grafik 5. Pola Perkembangan Penjualan SIR 20

Sumber: Data Sekunder diolah dari PT. Perkebunan VII Unit Padang Pelawi 2009-2015

Perencanaaan Untuk 1 Tahun Mendatang untuk Pasokan dan Harga bahan baku, harga dan Penjualan SIR 20.

Dengan adanya perhitungan peramalan menggunakan software e-views dengan data pasokan bahan baku dari dalam dan luar perusahaan pada PT. Perkebunan VII Unit Padang Pelawi diketahui bahwa metode Arima memiliki nilai kesalahan/error yang terkecil. Kemudian metode tersebut dapat dijadikan sebagai perencanaan/dasar dalam meramalkan pasokan bahan baku dari dalam dan luar perusahaan yang menjadi masalah bagi perusahaan dalam memproduksi Standard Indonesia Rubber (SIR). Perencanaan untuk 1 tahun mendatang dapat dilihat pada grafik dibawah ini.

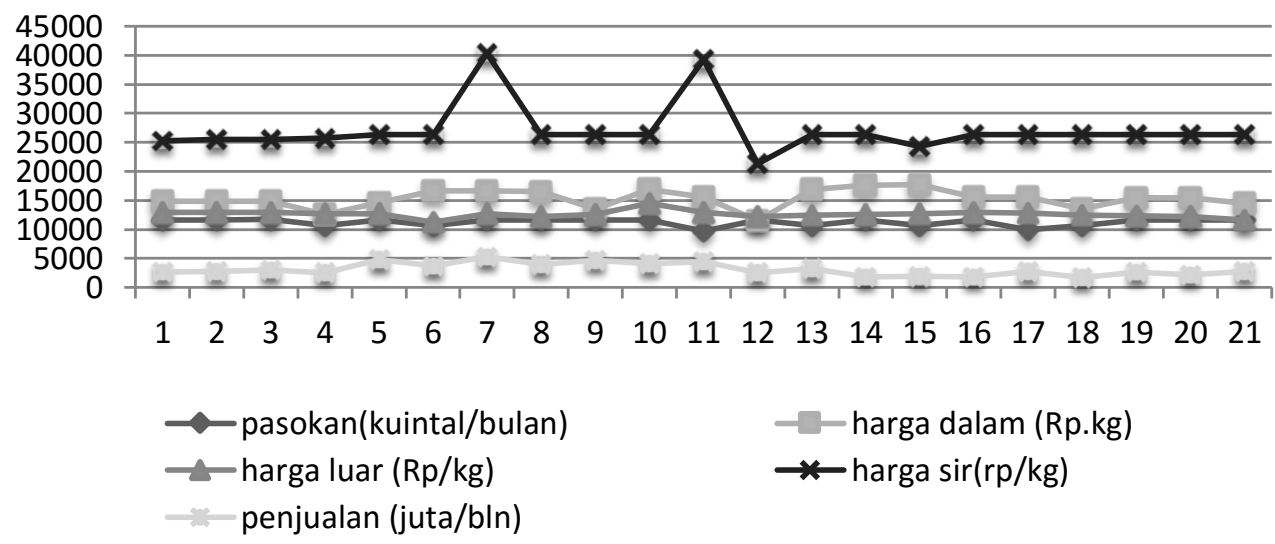

Grafik 6. Perencanaan Pasokan dan Harga Bahan Baku, Harga dan Penjualan SIR 20 
Berdasarkan Grafik 6 dapat diketahui bahwa pasokan dan harga bahan baku, penjualan dan harga SIR mengalami fluktuasi. Pasokan tertinggi pada bulan juni (11.676,66 kuintal/bulan) dan terendah pada bulan februari 2016 (9.656,13 kuintal/bulan), harga bahan baku dalam perusahaan tertinggi pada bulan juni 2016 (Rp 17.770 /bulan) dan terendah (Rp 11.550/bulan), untuk harga bahan olahan karet rakyat dari luar perusahaan tertinggi pada bulan januari 2016 (14.456 Rp.bulan) dan terendah pada bulan september 2015 (Rp 11.200/bulan), untuk harga SIR 20 tertinggi pada bulan oktober 2015 (Rp $40.343,57 /$ bulan) dan terendah pada bulan maret 2016 ( $\operatorname{Rp} 21.314,77 /$ bulan) dan untuk penjualan tertinggi pada bulan oktober 2015 (5.284,27 Juta/bulan) dan terendah pada bulan september 2016 (1.629,463 juta/bulan). Grafik diatas menunjukkan bahwa pada saat harga SIR meningkat, maka berbanding lurus dengan jumlah penjualan. Pada bulan oktober 2015 jumlah dan penjualan SIR 20 meningkat, sedangkan pada saat grafik pasokan bahan baku meningkat berbanding terbalik dengan harga bahan baku yang semakin menurun. Dapat disimpulkan ketika pasokan bahan baku tinggi maka harga bahan baku luar perusahaan akan menurun. Pada grafik harga bahan baku terjadi perpotongan, saat grafik harga bahan baku dalam perusahaan menurun maka jumlah pasokan bahan baku akan meningkat. Oleh sebab itu rencana dan strategi harus dipersiapkan oleh perusahaan dalam mengoptimalkan jumlah pasokan, harga dan penjualan dengan efisien.

\section{SIMPULAN DAN SARAN}

\section{Simpulan}

1. Berdasarkan pola perkembangan bahan baku dari (dalam dan luar perusahaan), harga bahan baku dalam dan luar perusahaan, harga Standard Indonesia Rubber (SIR), harga penjualan Standard Indonesia Rubber (SIR) secara menyeluruh mengalami peningkatan berdasarkan persentase Indeks musim.

2. Hasil peramalan bahan baku karet dari dalam dan luar perusahaan menunjukkan bahwa metode terbaik adalah metode Arima $(1,1,1)$, untuk harga bahan baku dalam perusahaan metode terbaik adalah metode Arima $(1,0,1)$, untuk harga dari luar perusahaan metode terbaik adalah Arima $(1,0,1)$, untuk harga Standard Indonesia Rubber (SIR) metode terbaik adalah Arima $(1,1,1)$ dan untuk penjualan SIR metode terbaik adalah metode Arima $(1,0,1)$ menunjukkan bahwa metode Arima merupakan metode time series yang sesuai dan cocok untuk data stasioner dan musiman.

3. Ramalan untuk 1 tahun mendatang yang dimulai dari april 2015 sampai desember 2016 sangat bervariasi, sehingga menjadi acuan dasar bagi PT. Perkebunan Nusantara VII Unit Padang Pelawi untuk membuat kebijakan dan menerapkan beberapa sistem manajemen yang tepat dan efisien agar target-target perusahaan tercapai.

160 | Eka Monika M., M. Mustopa, R., dan Nusril, Peramalan Pasokan Bahan... 


\section{Saran}

1. Perusahaan PT. Perkebunan Nusantara VII Unit Padang Pelawi sebaiknya memilih metode terbaik dengan tingkat kesalahan terkecil yaitu metode Arima yang dapat digunakan sehingga dapat mengurangi ketidakpastian dimasa akan mendatang dengan hasil ramalan yang tidak jauh berbeda dengan realisasi.

2. Agar perusahaan menggunakan software e-views untuk peramalan (forecasting) sehingga dapat meningkatkan kemampuan manajemen perusahaan.

3. Pabrik sebaiknya melakukan standarisasi mutu. Turunnya harga karet disebabkan melemahnya standar mutu/berat bersih yang dijual petani disebabkan oleh kurangnya pengetahuan terhadap standar kualitas karet sehingga berdampak pada kualitas produk yang dihasilkan.

4. Perbaikan ekonomi global, Tantangan eksternal dari rentannya perbaikan global sehingga berdampak pada kinerja ekspor nasional, dan tantangan domestik berasal dari pencapaian produksi hasil perkebunan yang kurang optimal serta terbatasnya infrastruktur perekonomian.

5. Implikasi manajerial untuk harga SIR 20 yaitu sebaiknya kualitas SIRnya ditingkatkan sesuai dengan keinginan konsumen agar dapat memasuki pasar dunia sehingga penjualannya bisa berjalan dengan lancar.

\section{DAFTAR PUSTAKA}

BPS. 2013. Kontribusi Subsektor Perkebunan pada Pertaniaan. Bengkulu.

Gasperz, Vincent. 2004. Production Planning and Inventory Control. PT Gramedia Pustaka Umum. Jakarta.

Jarwanto. 2000. Intermediate Accounting. Edisi 12. Vol. 1. Erlangga. Jakarta.

PT. Perkebunan Nusantara VII Unit Padang Pelawi. 2014. Pasokan Karet Remah, Bokar dan Produksi SIR 20. Bengkulu. 
